\title{
Special Edition on Economic Issues: An Introduction
}

\author{
By Guthlac Nkem Kirk Anyalezu *
}

In this special edition of the journal are six diverse research papers ranging from management to infrastructure development. The objective is to offer a rich broad research interests that falls within the scope of the institutes mission in promoting scholarships and dissemination of knowledge through education and research. More interestingly is the opportunity the journal offers to $\mathrm{PhD}$ research students to show case the research interest they are working on. Most of these research papers are still at the development stage and as such are far from completion. In other words, they are in essence work in progress and require substantial improvement work. The primary theme therefore in this introduction is not about providing critiques of the research papers. The main thrust is to present the reviewed works done so far in each of studies.

I therefore commence this introductory section with a paper by Jin, Vardiabasis, and Seaman, titled "Predicting financial crises: draw probabilities as leading indicators". The paper examines the utilization of sequential draw probabilities for two players, represented here by the banking and enterprise sectors, in predicting potential financial crises. The perception or assumption was that financial crises arise following cyclical patterns of up and down turns induce by underlying economic mechanism. Thus, the expectation of risk transfers between the financial sector and the real economy as one such mechanism. The paper analytical results suggest for a system that is capable of been employed to assess the proximity and possible intensity of financial crisis. This evidence manifests by comparing the competitive differences in Return of Equity (ROE) between banks and the enterprises, which is assume can help in measuring asymmetry of risk. The conclusion was that the growing asymmetry in risk indicates a potential threat of financial distress. Hence, there is a possibility of gathering more evidence on crisis proximity, with the study extending to include analysis of risk allocation across economic entities and sectors.

The comparative analysis of the autoregressive equation that describes the generating information process of inflation in regards of a methodological change of Puerto Rico's consumer price index (CPI) paper was by Rodriguez. This research paper focuses on the variation in the autoregressive (AR) structure of inflation due to a methodological change in the CPI of Puerto Rico. The study implies that the demand and supply forces, the USA monetary policy and the transformation of the Puerto Rico economy had significantly affected the inflation. The study is a time series methodological analysis utilizing statistical analysis, lag length criteria, correlogram, unit root and structural tests. The purpose for the approach is to develop the generating information process that will provide the dynamic structure of the series of the inflation with the 1984 and 2006 bases. The

\footnotetext{
${ }^{*}$ Professor of Economics, University of Phoenix, USA and Austin Community College, USA.
} 
study results shows that with the new methodology, it highlights a more stable behavior and close to have a unit root process.

The next paper to introduce here is "The infrastructure development in the Republic of Guinea" by Lan, Chen and Lim. The paper highlights the empirical studies indication of the significant contribution of infrastructure to economic development, and in particular, the long run economic growth. Hence, the keen interest by academics and policy makers to issues relating to infrastructure. This study explores the current infrastructure development in Guinea. The data source for the infrastructure construction was from the statistic department of the Republic of Guinea. To test for the proposed theoretical framework, the study adopted the Cobb-Douglas production function. The findings indicate that infrastructure has a positive spillover externality on the long run economic growth. This is especially, the significant influence on economic growth by the electricity consumption in the economy; thus, prompting the suggestion for the Republic of Guinea to invest in infrastructure.

My next introductory discussion is a paper by Brunsson with the title, "A dual perspective on management". This paper focused on the need for management teachings, which presumably, is significantly distinct from any experience of managerial practice. The implied assumption is that the teachings of management are essential component in the social construction of organizations. Therefore, it should constitute a salient part of the organizational economy that dominates society. The assertion or postulation in this case is that, the teaching of management cannot be from a practice perspective only, but dualistically as a coherent set of ideas. That is, as a doctrine, and as it may turn out in practice. In other words, the teaching of management should be simultaneously trusted and distrusted, and all students of management should master the capacity to embrace contradictory views on the issue of management.

The next paper in this special introduction is the study by Henson and Garfield, "What attitude changes are needed to cause SMEs to take a strategic approach to information security". The view expressed in the study was that expenditure on security in SME often has to compete with demands for hardware infrastructure and strategic applications. Furthermore, the authors seek to explore the reasons why smaller SMEs in particular have consistently failed to see securing information as strategic year on year spending. The assertion was to regard such expenditure as part of an overall tight information technology (IT) budget. The study scrutinizes the typical SMEs reasoning for choosing to see nonspending on security as an acceptable strategic risk. Thus, the concentration at the possible reasons SMEs tend not to take much notice of "scare stories" in the media based on research indicating they are increasingly at risk. On the other hand, larger businesses exercise greater precautions, thus ensuring difficulty to penetrate. The study results and analysis claim to provide some useful indications towards broader business environment changes that would cause SMEs to be more riskaverse and ethical in their approach to securing their own and their client's information.

Finally, I discuss here the study by Garcia-Meza, Neme-Castillo and Valderrama-Santibanez, "Innovation in Mexican micro and small businesses: 
individual skills and knowledge". The study assume the path to increase value added to micro and small businesses (MSB) is by innovation and as such commences from an intellectual capital with skills, attitudes, motivation and knowledge being the salient features. Furthermore, innovation is assume as a process emanating from the formation of skills for labor and education or training and experience leading to individual innovation. In which case, externalities such as skills translate into successful innovation processes; that is, generation, development or modification of products and processes. Equally, in transit through the spiral of innovation involving one step of creativity and one of entrepreneurship, three interrelated types of human skills come into force: basic, secondary and innovative. Thus, the aim for the study is to describe the importance of the individual skills and knowledge to the innovation process in Mexican MSB.

In conclusion to my introduction to this special edition of the journal on economic issues, the studies has certainly made some very interesting thought provoking insights irrespective of the school of thought one belongs. Never the less, each of these research studies presents a different challenge. However, they all share a common norm, which is seeking ways to improve economic development, limit financial distress and economic growth slow down. The most important economic issue of it all is about encouraging for economic productivity, efficient and effective investment in infrastructure and development, as well as for good economic management. 
